\title{
Personal construct psychology in education and learning
}

\author{
Maureen L. Pope \\ University of Surrey \\ AND \\ MildRed L. G. Shaw \\ Middlesex Polytechnic at Trent Park
}

(Received 30 September 1979, and in revised form 2 October 1980)

\begin{abstract}
Recently educational technology has undergone a change of emphasis in the methods and means of teaching: from mass instruction through individualized instruction to group learning. This re-orientation parallels developments within education itself of the three stages of dependent, independent and interdependent learning. This paper discusses the contribution which can be made to this development by personal construct psychology, and in particular the practical role in it of the PEGASUS and SOCIOGRIDS programs for construct elicitation and analysis.
\end{abstract}

\section{Introduction}

In recent years there has been increasing discontentment with the models of learning upon which education and training are based. Much of the emphasis in this paper is on education in schools and colleges, but it is suggested that the issues raised are equally relevant to education and training in the wider sense, at work and at play. Hayes (1978) suggests a closer alignment of education, training and work, and indicates that "learning-to-learn" is as important a concept for industry and commerce as it is becoming within schools and colleges. There is growing recognition within industry of the need for establishing the personal strategies used and the values held by the learner in relation to any particular learning task. New techniques are evolving which encourage the individual learner to confront these aspects and to take an active and responsible part in the learning process. Each of us has an implicit model of the learning process which will have an impact on our behaviour as learner or teacher/trainer.

The theories underlying the practice of educational research are also intimately linked to general educational ideologies. These educational ideologies embody theories of the nature and development of man. As Bruner (1966) pointed out-instruction can be seen as an effort to assist or to shape growth and that any theory of instruction is in effect a theory of how growth and development are encouraged. Any theory about teaching is thus inextricably linked to an underlying view or model of the nature of the learner. A teacher/trainer may conceive of the nature of the learner as active or passive, or meaning seeking, or impulse driven, fixed or constantly developing. Whichever model is adopted will influence that teacher's teaching strategy and objectives.

Much of the current debate on education revolves round fundamental differences in the models of learning held by the individuals concerned. Many educationalists argue 
that a major problem is that at any point in time educational issues tend to be dominated by one particular viewpoint or "frame of reference" so that education becomes monolithic in structure (Joyce, 1972). Those involved in education often adopt rigidly opposing positions which mitigate against a more constructive and flexible approach. There is now a growing recognition that alternative-models can co-exist and enrich rather than detract from development in education. Some educational researchers are seeking new approaches-recognizing that past educational research has been conducted on too narrow a base. Snow (1974) discusses these issues in relation to research on teaching and suggests that we should be concerned with (Snow, 1974, pp. 288-289):

Adapting methodology to match the complexity of students and situations in schools.... Hopefully in future programmes of research, alternative kinds of designs will be used and various hybrids will be invented so that the advantages and disadvantages of each can be counter-balanced and more clearly understood.

Repertory grid techniques evolving from the work of George Kelly (1955) are proposed as one possible alternative mode of inquiry within educational research. This is an alternative methodology which will allow both the researcher/teacher and participant subject/learner a means of monitoring and reflecting on the idiosyncratic frames of reference which the learner evolves. Rather than the imposition of a monolithic approach to educational issues, a Kellian framework allows for diversity of viewpoints and constructive alternatives in education. This paper will discuss the development of resource tools which have their roots within Personal Construct Psychology and which are now being applied within a variety of learning contexts. Educational Technology in the past has concerned itself with dependent learning situations. Recently emphasis has been placed upon independent and interdependent learning (Elton, 1977) and the PEGASUS and SOCIOGRIDS programs derived from repertory grid techniques (Shaw, 1980) have been applied to these areas. These are also applicable in the areas of computer assisted learning, self-organized learning in education and industry, study counselling or management development.

\section{An ideological context}

Traditionally the educator's job was seen to be the direct instruction of information and rules, and education was seen as the transmission of the culturally given. For example, Robert Maynard Hutchins (1936, p. 66) wrote:

Education implies teaching. Teaching implies knowledge. Knowledge is truth. The truth is everywhere the same. Hence, education should be everywhere the same.

Much of the basis of Educational Technology and behavioural modification approaches to education can be seen as variants of this cultural transmission approach. Knowledge and values are seen as located in the culture and are internalized by children imitating adult behaviour models or through explicit instruction and the use of such training procedures as reward and punishment. The criterion of successful education for such theorists is the student's ability to incorporate the responses he has been taught and to respond to the demand of the system.

Skinner (1968) views teachers as architects and builders of student behaviour. He defines learning as a change in the probability of response. He seeks to explain all human behaviour in terms of respondents and operant reinforcement. Through pro- 
gressively changing the contingencies of reinforcement in the direction of the desired behaviour (as defined by the teacher) learning is seen to occur. Educational change is evaluated from performances, not from changes in thoughts or feelings. Traditional teaching methods are often referred to as "expository presentation" or "receptive" learning methods which emphasize the student's role as the passive receiver of information rather than the active participant. The dominant idea was that students do not have sufficient self-direction to work out educational programmes in collaboration with their teachers thus the students had little or no control over the manner in which they are taught and curriculum content.

This view of teaching and learning has dominated western education and has been supported by psychological theories of development which stress the passivity of man's mind-associationism, behaviourism, stimulus-response psychology, contingency theories, etc. However, in the last few years we have seen a paradigm shift within psychology and education resulting in a renewed interest in the individual's active processing. Knowledge is seen as being produced by transaction between man and his environment and an emphasis is now placed upon an active man reaching out to make sense of his universe by engaging in the reconstruction and interpretation of his own experiences. Following in the traditions of Rousseau and Dewey, modern educationalists maintain that learning should be directly related to the interests of the person; motivation to learn should come from within the person rather than knowledge be imposed upon him. The teacher is seen more as a guide or adviser in a process whereby the person reconstructs the subject matter in accordance with its perceived relevance to his own life.

The teaching methods upheld by Progressivism encourages student-student interaction as well as student-teacher interaction. The teacher is interested in students developing their own criteria regarding the quality and relevance of ideas and he allows this to develop by minimizing his role as an arbiter of what is acceptable. His aim is not the transmission of "nuggets of truth" rather he aims to facilitate the process of learning and the acquisition of personal potency (Brown, 1971).

Many educationalists are now concerned with the active involvement of the learner. For example (Postman \& Weingartner, 1971, p. 59):

There is no way to help the learner to be disciplined, active and thoroughly engaged unless he perceives a problem to be a problem, or whatever is to be learned to be worth learning, and unless he plays an active role in determining the process of solution.... It is sterile and ridiculous to attempt to release the enquiry power of students by initiating studies that hold no interest for them.

Kelly recognized learning as a personal exploration and saw the teacher's role as helping

to design and implement each child's own undertakings.... To become a fully accredited participant in the experimental enterprise she must gain some sense of what is being seen through the child's eyes. (Kelly, 1970b, p. 262.)

What is relevant to the person is of importance and for education to be a joint venture between teacher and learner it is essential that each has some awareness of the other's personal constructs. The perspective of the student as well as that of the teacher must be considered although traditionally learning has been defined mainly from the latter's perspective. 


\section{Perspective of the personal}

Many writers on educational issues, e.g. Blumer (1966), Hargreaves (1972) and Morris (1972), have argued that it is time that recognition be given to the perspectives of the people engaged in classroom interaction. Blumer (1966) writing on educational research, suggests that (p. 542):

Since action is forged by the actor out of what he perceives, interprets and judges, one would have to ... take the role of the actor and see his world from his standpoint.

This "perspective of the personal" is central to the work of George Kelly. It is implicit in the title of his theory-Personal Construct Theory-and explicit in his writings, e.g. (Kelly, 1970a, p. 9):

We start with a person. Organisms, lower animals, and societies can wait.

The fundamental postulate of Personal Construct Theory, now more popularly called Personal Construct Psychology (P.C.P.), is that "a person's processes are psychologically channelised by the ways in which he anticipates events". For Kelly, man's behaviour is not driven by instincts (as in psychoanalytic theory) nor is it determined by the schedules of reinforcement and associations between stimulus and response (as in Skinnerian and Behaviourist theories). There have been many analogies used in psychology: man - the telephone exchange, man-the hydraulic system, and recently man-the computer. Kelly's analogy was man the scientist. Man the scientist and scientist the man are both engaged in a process of observation, interpretation, prediction and control. According to Kelly, each person erects for himself a representational model of the world which enables him to chart a course of behaviour in relation to it. This model is subject to change over time since constructions of reality are constantly tested out and modified to allow better predictions in the future. Thus for Kelly the questioning and exploring, revising and replacing in the light of predictive failure which is symptomatic of scientific theorizing, is precisely what a person does in his attempts to anticipate events. The person can be seen as a scientist constantly experimenting with his definition of his existence. For Kelly man is himself "a form of motion"-thus he denies the necessity of "carrot and stick" or "impulse driven" theories of motivation. Man is constantly attempting to make sense of his environment and man's anticipation of future events is "both the push and pull of the psychology of Personal Constructs" (Kelly, 1955, p. 49). Kelly does not deny the importance of early experiences or present environmental circumstances but he suggested that it was more important to know what and how a person thinks about his present situation than to know what his early childhood experiences were or in what environmental circumstances he now finds himself.

The "Progressive" movement in education emphasizes the activity of the person struggling to impose meaning on his experiences and rejects the notion of a passive receiver of knowledge. The following quotation from Berman \& Roderick $(1973$, p. 3) indicates some assumptions re curriculum which appear to us to be compatible with Kelly's viewpoint.

Curriculum has long been thought of as that which is taught to somebody else... . The view of these writers is that curriculum must put the person at the centre of what is learned.

Curriculum development and subsequent research on the curriculum will then see the person as the meaning maker and plan curricula experiences which enable the child to 
consider, contemplate, and expand his meanings. Critical to curriculum development, then, is the ascertaining of what is happening to the individual child as he interacts with persons, materials, time and space within the context of the school and the classroom.

This emphasis on the person as the meaning-maker is central to Kelly's position. In order to understand a person's behaviour it is necessary to know how he construes his particular situation. Kelly argues that persons differ from each other in their construction of events (individuality corollary). Lambert et al. (1973) discussed the limits of structural analysis of the education system which has become prevalent in recent years. A major assumption of this approach is that structural variables of a school are directly related to aspects of its pupils' society. Kelly would not presume that members undergoing a similar education system or belonging to particular groups would necessarily share the same system of construing. However he did admit the possibility of shared areas of personal meaning and this was made explicit in his commonality corollary (Kelly, 1970a, p. 20):

To the extent that one person employs a construction of experience which is similar to that employed by another, his processes are psychologically similar to those of the other person.

However, it is Kelly's stress on the personal nature of meaning and the elevation of the person to the central focus of inquiry that aligns him with much of contemporary theorizing on education.

\section{A technology}

Kelly (1969, p. 135) maintained that

humanistic psychology needs a technology through which to express its humane intentions. Humanity needs to be implemented not merely characterised and eulogised.

Humanistic psychologists and educators must develop technologies appropriate to their orientation, i.e. tools which help in the articulation of personal perspectives. We would suggest that the computer programs PEGASUS and SOCIOGRIDS are tools which meet this purpose. One of the main advantages of the PEGASUS program for the interactive elicitation of a repertory grid with on-going feedback to the user of highly matched elements and constructs (Shaw, 1980), is that it is content-free. School children, university students, housewives, lecturers and managers have all used the program to construe a variety of elements related to a wide variety of purposes. Examples of these have been significant learning events, audio-visual equipment, architectural styles, examination scripts, prospective careers, mathematical concepts and books.

Figure 1 shows a FOCUSed grid (from Shaw, 1980) which was given at the end of a PEGASUS run. Arthur, who produced this grid, defined his purpose for using PEGASUS as "exploring learning situations". When a high match was found between the elements "tutorial" and "seminar" feedback was given to him, and he was invited to add a construct to distinguish between them. He added the construct "small grouplarge group" and subsequently rated all the elements on this new construct. At a later stage when a high match between the two constructs "flexible-rigid" and "variable content-specific content" was found by the computer, this was pointed out and Arthur was asked to add an element which was "either flexible and specific content or variable 


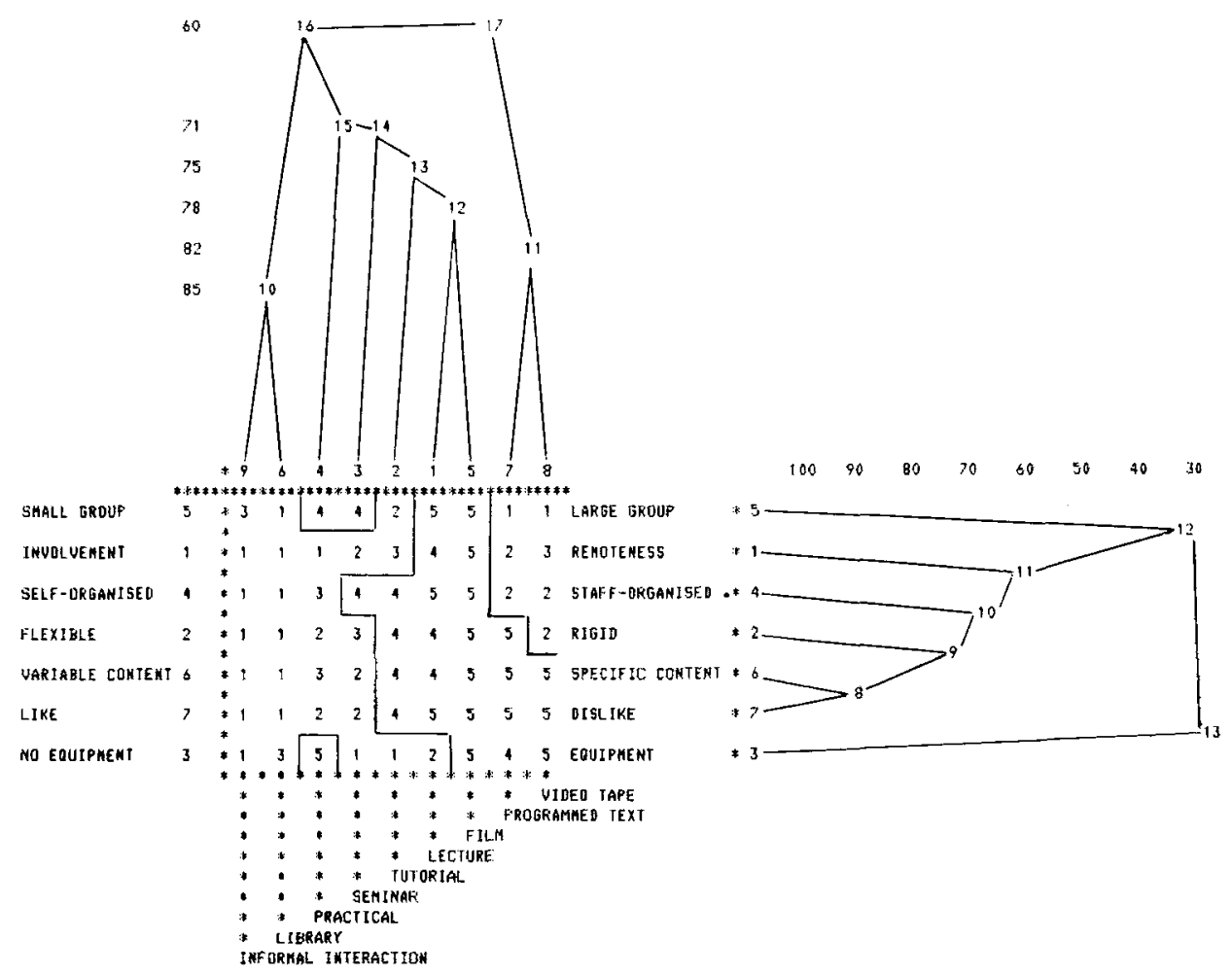

Fig. 1. Arthur's FOCUSed grid from PEGASUS.

content and rigid". He decided to add the element "video tape" which he said was "flexible" and "specific content". Very little structure is imposed on the user and a variety of choice is given wherever possible, thus allowing the learner to choose the level and direction of reflection on his ideas.

It is of course necessary for the learner to relate his construction of personally relevant meaning to bodies of established knowledge and traditional educational disciplines. PEGASUS-BANK is a development of PEGASUS which allows the user to complete a grid on a topic area and get ongoing feedback on the relationships between his constructs and those of "an expert" or the consensually validated definitions which represent public knowledge in the area. We have found that if a tutor and student complete grids on the same topic area this provides a basis for discussion. Externalizing areas of similarity and dissimilarity between a tutor's grid and that of the student gives a framework for negotiation of differences between tutor's and student's perspectives. This leads to a greater awareness and understanding of the other's point of view. If the technique of grid-elicitation together with grid-feedback is used in a "learningcentred" way personal models can be brought into awareness, revised and refined, or even rebuilt to enable learning to be more successful in those areas where inadequate modelling was hindering the learning process.

The SOCIOGRIDS program is used in order to explore the similarity and differences in construing between members of a group. This technique is based on an assumption rooted in Kelly's commonality corollary that there may be areas of shared meaning 
among any group of individuals. Starting with the negotiation of a common set of elements by the group concerned, this program analyses the set of repertory grids elicited from the group. Each person is free to use his/her own personal constructs. Similarity between constructs is not based upon literal similarity but upon an operational definition of similarity in terms of the ordering of the element set.

Using the SOCIOGRIDS technique each individual in the group has feedback on his own mapping of the area from a FOCUSed grid (as in Fig. 1). In addition the "mode"grid of the most commonly used constructs by all the members of the group is extracted and focused, exhibiting the content of the shared construing in the group. Figure 2 illustrates this mode grid from a group of three staff and four students on education courses in a polytechnic (from Kevill \& Shaw, 1980). This was the subgroup having common elements of an initial group of 20 staff and students who had elicited grids to investigate views of the methods of communication used on their courses in the polytechnic.

It appears that there are a number of constructs with the underlying idea of personal contact and participation by the individual, e.g. constructs $9,3,6,7$. For some people slightly different meanings are attributed to almost identical words, e.g. constructs 3 and

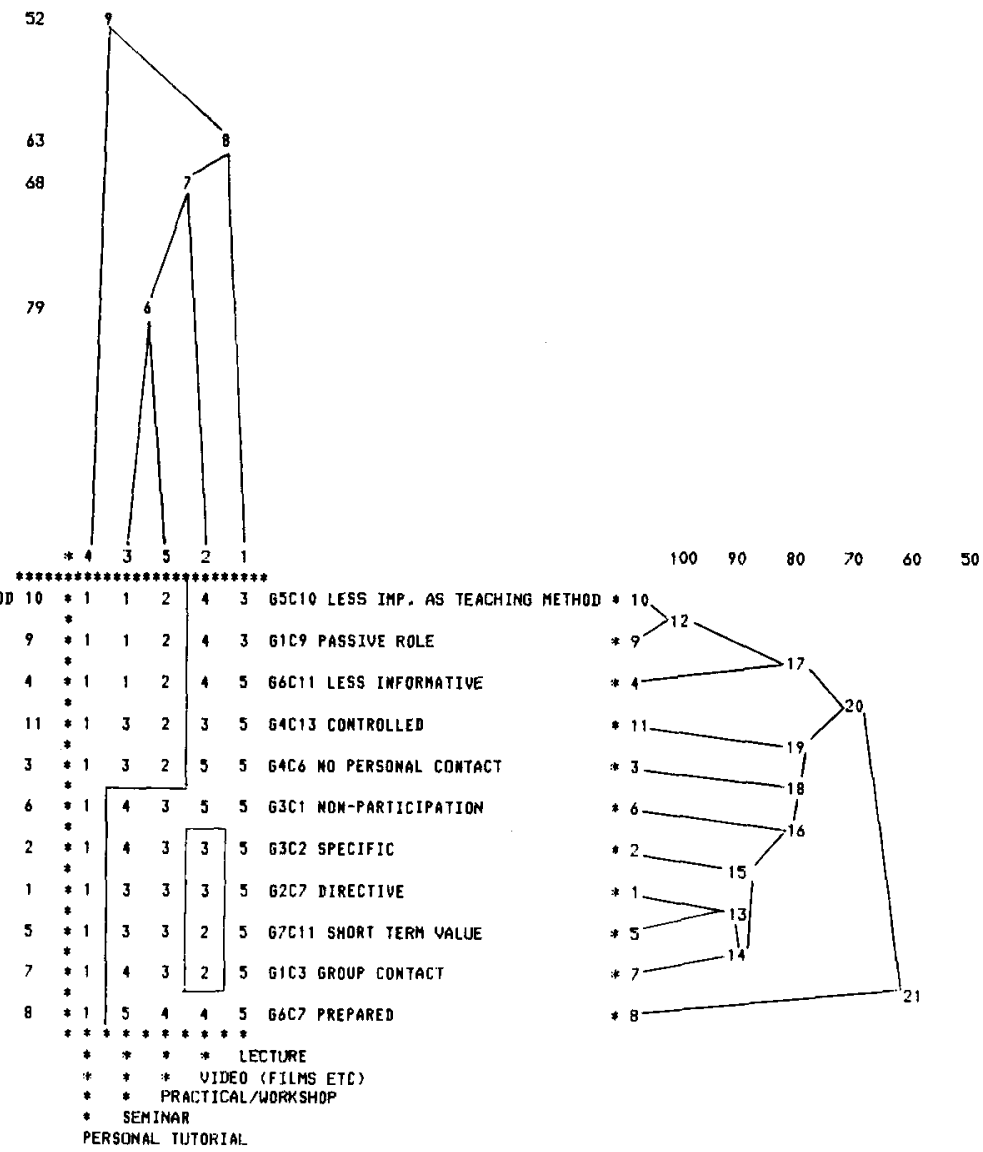

Fig. 2. The FOCUSed mode grid. 
7, whilst for others different words are used to express the same ordering of elements, e.g. constructs 9 and 10 .

The program also produces a sequence of "socionets" from the matrix of similarity measures between pairs of individual grids. The highest related pair in a group can be extracted as a sub-group where the most commonality of construing occurs and subsequent individuals can be defined by their position in the rank ordering of the similarity measures. Thus, this set of socionets exposes those members of the group who have most in common and those with strongly individualistic viewpoints.

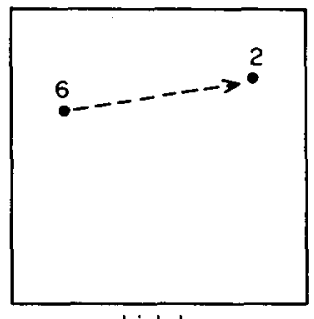

Link I

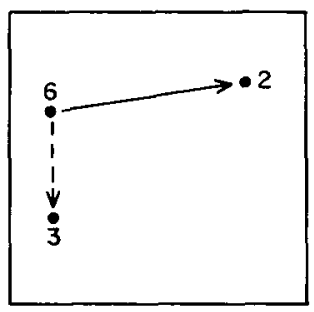

Link 2

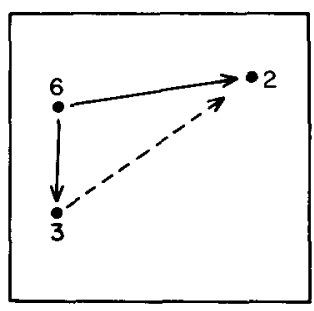

Link 3

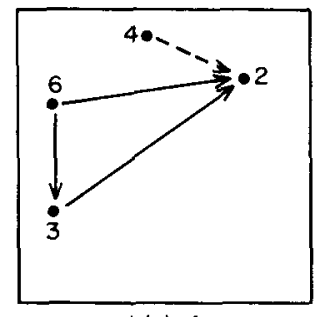

Link 4

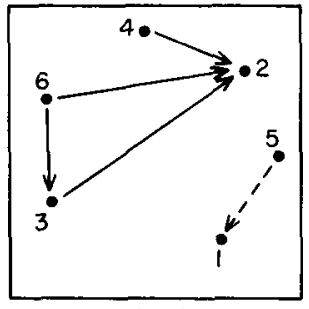

Link 5

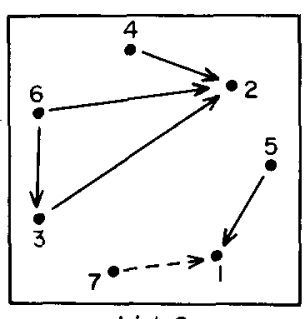

Link 6
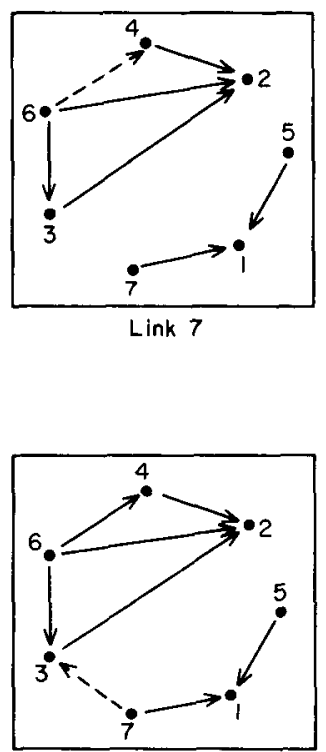

Link 8

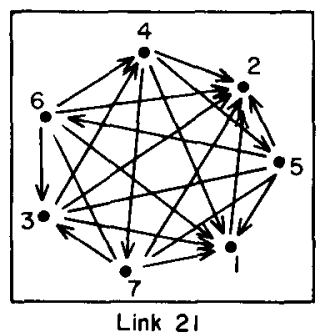

FIG. 3. Part of the sequence of socionets from SOCIOGRIDS.

Figure 3 shows part of the sequence of socionet diagrams from the same group of staff and students. It is interesting to note that all seven members are involved by link 6 showing a high degree of commonality, although at this stage there are two separate subgroups. In the final diagram (link 21) it is interesting to see the direction of the arrows, indicating a wider construct system on the left. Subjects 5,6 and 7 have all but 
one arrow leading from them indicating an understanding of the others, whilst subjects 1 and 2 have all the arrows pointing towards them, indicating a narrower view. Subjects 5,6 and 7 are members of staff, and subjects 1 and 2 are students.

\section{Conclusion}

The SOCIOGRIDS method represents a technological advance which allows the learner to reflect on his personal model whilst offering each member of the group the facility to become aware of the inter-relationships between ideas within the group. It has been our experience that learners become very involved in the process of reviewing similarities and negotiating the differences within the group and find it a relevant learning experience. In some cases it has been the first time the person has dwelt upon the notion of relativity in constructions of reality.

Esland (1971) suggested that, in education, knowledge itself must be dereified. The SOCIOGRIDS program certainly helps this process of dereification. Esland noted that, once dereified, knowledge then becomes (p. 96):

a much more negotiable commodity between teacher and pupil. Its social-historic relativity is likely to be transparent and the content of knowledge may become subservient to the development of a cognitive technology which is capable of projecting multiple inferential structures containing both enactive and theoretical knowledge.

He suggested that new configurations of knowledge arise from questioning in learning situations and that boundaries between "subjects" are "only human constructs and can, therefore, be broken".

For Kelly the construction of reality is an active, creative, rational, emotional and pragmatic affair. Man the scientist evolves a set of constructions which he tests out and may ultimately discard in favour of a new set of constructions if the former fails to anticipate events adequately. Kelly pointed out that all theories are man-made hypotheses which may fit all the known facts at any particular time but may eventually be found wanting in some unforeseeable respect and eventually replaced by a "better theory". An example from physics is the re-appraisal of Newton's theory by Einstein. However Einstein's theory is not the ultimate truth-Einstein himself regarded his theory as defective and spent much of his life trying to find a better one. In putting forward his theory, Kelly suggested that as a theory it would be subject to revision since it is itself an example of a human construct and so can be seen as an hypothesis waiting to be put to the test.

This view of theory, science and knowledge is echoed in the writings of Karl Popper (1963). He sees science and knowledge as progressing through a series of "conjectures and refutations". Kuhn (1970) analyses the progress of science and suggests that growth of knowledge occurs when the dominant paradigm of the day is challenged by the revolutionaries who step outside the limits of present theory and engage in what Kuhn calls "extraordinary science". Kuhn suggests that professional scientists are educated in the "normal" scientific mode which involves solving problems within the limits of the theory the scientist has been taught. The theory itself is not questioned. If problems are not solved the theory is not invalidated, the scientist lacks ingenuity! PEGASUS and SOCIOGRIDS offer teachers and learners a resource which encourages the individual to reflect on his conceptualizations of his world and an opportunity to explore differing 
conceptions. Active involvement with his own and others' ideas may encourage the learner to see himself as a more potent force in the determination of his own learning and in the development of new knowledge.

We are grateful to Terry Keen and Nan Kevill for discussions and the use of data.

\section{References}

BFRMAN, L. M. \& RODERICK, J. A. (1973). The relationship between curriculum development and research methodology. Journal of Research \& Development in Education 6, (3) 3-13.

Bl.UMER, H. (1966). Sociological implications of the thought of George Herbert Mead. American Journal of Sociology, 71, 535-548.

BROWN, G. T. (1971). Human Teaching for Human Learning. New York: Viking Press.

BRUNER, J. S. (1966). Towards a Theory of Instruction. New York: Norton.

ELTON, L. R. B. (1977). Educational Technology today and tomorrow. In Aspects of Educational Technology (GILBERT, J. K. and Hills, P. J., Eds). London: Kogan Page.

ESLAND, G. M. (1971). Teaching and learning as the organisation of knowledge. In Knowledge and Control (YOUNG, M. F. D., Ed.). London: Collier-Macmillan.

HARGREAVES, D. H. (1972). Interpersonal Relations and Education. London: Routledge and Kegan Paul.

HAYES, C. (1978). Groundwork for a flexible future. Personnel Management, pp. 27-29 (March).

Hutchins, R. M. (1936). The Higher Learning in America. Newhaven, Conn.: Yale University Press.

JOYCE, B. (1972). Curriculum and humanistic education. In Humanistic Foundations of Education (Weinberg, C., Ed.). Englewond Cliffs, New Jersey: Prentice-Hall.

Kfelly, G. A. (1955). The Psychology of Personal Constructs Vols 1 and 2. New York: Norton.

KELLY, G. A. (1969). The strategy of psychological research. In Clinical Psychology and Personality: the collected papers of George Kelly (MAHER, B., Ed.). New York: Wiley.

KELLY, G. A. (1970a). A brief introduction to personal construct theory. In Perspectives in Personal Construct Theory (BANNister, D., Ed.). London: Academic Press.

Kfllly, G. A. (1970b). Behaviour as an experiment. In Perspectives in Personal Construct Theory (BAnnister, D., Ed.). London: Academic Press.

KFvill, F. M. \& ShAw, M. L. G. (1980). A repertory grid study of staff-student interactions. Psychology Teaching, 8, 29-36.

KUHN, T. S. (1970). Logic of discovery or psychology of research. In Criticism and the Growth of Knowledge (LAKetos, I. \& Musgrave, I., Eds). Cambridge University Press.

LAMBERT, R., BULLOCK, R. \& SPENCER, M. (1973). The informal social system. In Knowledge, Education and Cultural Change (BROWN, R., Ed.). London: Tavistock.

MORRIS, B. (1972). Objectives and Perspectives in Education: Studies in Educational Theory 1955-70. London: Routledge and Kegan Paul.

POPPER, K. (1963). Conjectures and Refutations: the Growth of Scientific Knowledge. London: Routledge \& Kegan Paul.

Postman, N. \& Weingartner, L. (1971). Teaching as a Subversive Activity. Harmondsworth: Penguin.

Shaw, M. L. G. (1980). On Becoming a Personal Scientist. London: Academic Press.

SKINNER, B. F. (1968). The Technology of Teaching. New York: Appleton-Century-Crofts.

SNOW, R. E. (1974). Representative and quasi-representative designs for research on teaching. Review of Education Research 44, 265-291. 